\title{
COMO AMARRAR O CÉU COM FIRMEZA?
}

How to firmly truss the sky?

Alberto Luiz de Andrade Neto ${ }^{78}$

\section{Resumo:}

Este ensaio se propõe a analisar o livro, "A queda do céu: Palavras de um xamã yanomami” (2010 [2015]), escrito pelo xamã e intelectual indígena Davi Kopenawa e o antropólogo Bruce Albert, com foco nos diálogos cerimoniais (hiimuu, wayamuи e о yãimuu) e nos discursos hereamuu yanomami. A partir deles, o texto se desenvolve em uma direção que assume os sonhos e a escuta como alternativas à face voraz e destrutiva dos não-indígenas em relação aos povos indígenas e à floresta

Palavras-chave: artes verbais; escuta; sonhos

\begin{abstract}
:
This essay aims to analyze the book "The falling sky: Words of a yanomami shaman" (2013), written by indigenous shaman and intellectual Davi Kopenawa and anthropologist Bruce Albert, focusing on ceremonial dialogues (hiimuu, wayamuu and yãimuu) and hereamuu yanomami speeches. From them, the text leads towards a perspective that assumes dreams and listening as alternatives to the voracious and destructive side of non-indigenous people in relation to indigenous people and the forest.
\end{abstract}

Keywords: dreams; listening; verbal arts.

${ }^{78}$ Doutorando em Antropologia Social pela Universidade Federal de Santa Catarina (UFSC). 
Agora estamos aqui

Porque aqui tem índios sonhadores

$(\text { Brô } M c ’ s)^{79}$

\section{Sonho (((escuta))) andança ${ }^{80}$}

No livro, "A queda do céu: Palavras de um xamã yanomami" (2010 [2015]), o xamã e intelectual indígena Davi Kopenawa e o etnólogo Bruce Albert, dizem que nós napëerl ("brancos") não sabemos sonhar, que nossos pensamentos são cheios de "fumaça" e "esquecimento", que falamos como "fantasmas", que enterramos nossos mortos no chão para os vermes comerem, que remexemos freneticamente a terra "como um bando de queixadas", que matamos uns aos outros sem nenhuma medida, entre tantas outras críticas. As contraposições a essas formas napë são os xamãs que viajam muito longe em seus sonhos, os seus pensamentos longos e cheios de clareza, os cantos apreendidos com os "espíritos da floresta" (os xapiri ${ }^{82}$ ), a ingestão das cinzas de seus mortos com mingau de banana, a proteção da urihi a ("terra-floresta"), a vingança ritual, e assim por diante. Perante essas críticas, haveria uma via de elaboração napë que pudesse considerar essas formas indígenas?

As reflexões sobre "formas indígenas" e "formas não-indígenas" são recuperadas das aulas de Etnologia Indígena (2019.1), ministradas pela professora Evelyn Martina Schuler Zea, no Programa de Pós-graduação em Antropologia Social da Universidade Federal de Santa Catarina (PPGAS/UFSC). Os objetivos e propósitos da disciplina, e aí estão incluídas as discussões sobre as "formas", eram estudar e debater o livro "A queda do céu" junto de outras produções bibliográficas de autores e autoras indígenas e não-indígenas, destacando os modos de diferenciação das configurações indígenas. Tratava-se de circundar as divergências nas formas de falar, sonhar, nomear, contar, narrar, fazer guerra, fazer política, entre outras, nesse tensionamento entre os napë e os povos indígenas. A estrutura da disciplina oferecida pela professora, sempre com generosidade e abertura em sala de aula, proporcionou um ambiente favorável para uma construção reflexiva coletiva - entre discentes, docente e a literatura selecionada - a qual criou movimentos de escuta e negociação em direção a frutíferos caminhos de aprendizagem.

Para seguir esse questionamento considero relevante um panorama que abarque os discursos, os diálogos cerimoniais e os sonhos tratados em "A queda do céu". Sztutman (2019) retoma também essa obra literária e indica os diálogos cerimoniais como alternativas para a "fala de fantasma" dos napë. No entanto, além de me debruçar sobre essas indicações, recupero ainda as reflexões sobre os sonhos para destacar as diferenciações entre os povos indígenas e os não-indígenas e, nesta direção, estender ponderações no sentido de uma cosmopolítica alternativa de relação com o planeta. Afinal, um dos grandes interesses do xamã e intelectual indígena ao lançar suas palavras é o de reascender a atenção e o respeito que não está sendo conferido à floresta. Como o próprio Kopenawa (2015) enfatiza: "Gostaria que os brancos parassem de pensar que nossa floresta é morta e que ela foi posta ali à toa. Quero fazê-los escutar a voz dos xapiri [...]. Quem sabe assim eles queiram defendê-la conosco?” (KOPENAWA: 65).

\footnotetext{
79 Trecho da música, Eju Orendive, do grupo Brô Mc's (2010).

${ }^{80}$ As imagens das "andanças" são inspiradas, livremente, nas pesquisas de Barbara Glowczewski (2015) e Tim Ingold (2011 [2015]).

${ }^{81}$ A palavra napë significa "forasteiro" ou "inimigo". É utilizada ao longo do livro "A queda do céu" para referir-se aos não-indígenas.

82 Segundo Albert (2015) “todo ente possui uma 'imagem' (utupë a, pl. utupa pë) do tempo das origens, que os xamãs podem 'chamar', 'fazer descer' e 'fazer dançar' enquanto 'espírito auxiliar' (xapiri a). Esses seres-imagens ('espíritos') primordiais são descritos como humanoides minúsculos paramentados com ornamentos e pinturas corporais extremamente luminosos e coloridos" (ALBERT, 2015: 610). Outras considerações podem ser vistas em: A floresta de cristal: notas sobre a ontologia dos espíritos amazônicos de Eduardo Viveiros de Castro (2006).
} 
Brevemente, o hiimuu, wayamuи e yãimuu são diálogos cerimoniais travados pelo povo indígena Yanomami. Já o hereamuu é um discurso proferido somente pelos homens mais experientes deste povo, porém também implica uma escuta atenta e é bastante enfatizado em "A queda do céu". Em termos gerais eles possuem o objetivo de expressar sabedoria (que tratam dos tempos ancestrais e das especificidades da floresta), funcionam ainda como ações diplomáticas e de resolução de conflitos (KELLY, 2017a; SZTUTMAN, 2019), anunciam as trocas por mercadorias (KELLY, 2017a e 2017b), podem levantar informes a respeito de questões cotidianas comunitárias e intercomunitárias (Idem), dentre outras.

A estrutura argumentativa desta pesquisa é construída com Pausas (\#1 e \#2), Propostas e Alternativas. Nas duas últimas o objetivo é trazer discussões com os diálogos cerimoniais, o discurso hereamuu e os sonhos como renovação no que tange a voracidade destrutiva dos napë - algo que, invariavelmente, retoma as argumentações erguidas em "A queda do céu". Já as Pausas são pequenos argumentos (livres) que emergiram junto à leitura do livro. O fim dessa caminhada pode ser entendido como um modo de costurar diálogos com diferentes ontologias e recuperar horizontes de conciliação com outras formas de estar no mundo.

\section{[Pausa \# 1: A raposa e as costas livres}

Em 2015, tive a oportunidade de visitar a exposição, “Ter as costas livres”, da artista Julia Amaral. O arranjo montado no Museu Victor Meirelles (Florianópolis - SC) trazia um conjunto de fotografias de insetos, pássaros e fungos. Alguns cogumelos fundidos em bronze foram posicionados no rodapé da sala de exposições, um pequeno crânio de pássaro fundido em metal ganhara lugar em uma das paredes, uma grande fotografia de uma raposa morta fora pendurada em algum trecho do percurso e um miúdo beija-flor, também morto, esteve presente na exposição da artista (Ver Figura 1).

O processo artístico de Amaral consiste na coleta de animais mortos, ossos e cogumelos encontrados, ocasionalmente, em suas caminhadas ou presenteados por seus amigos e amigas. A fotografia desses mesmos seres e/ou a transformação deles em esculturas metálicas foram alguns dos procedimentos encarados pela artista naquela época.

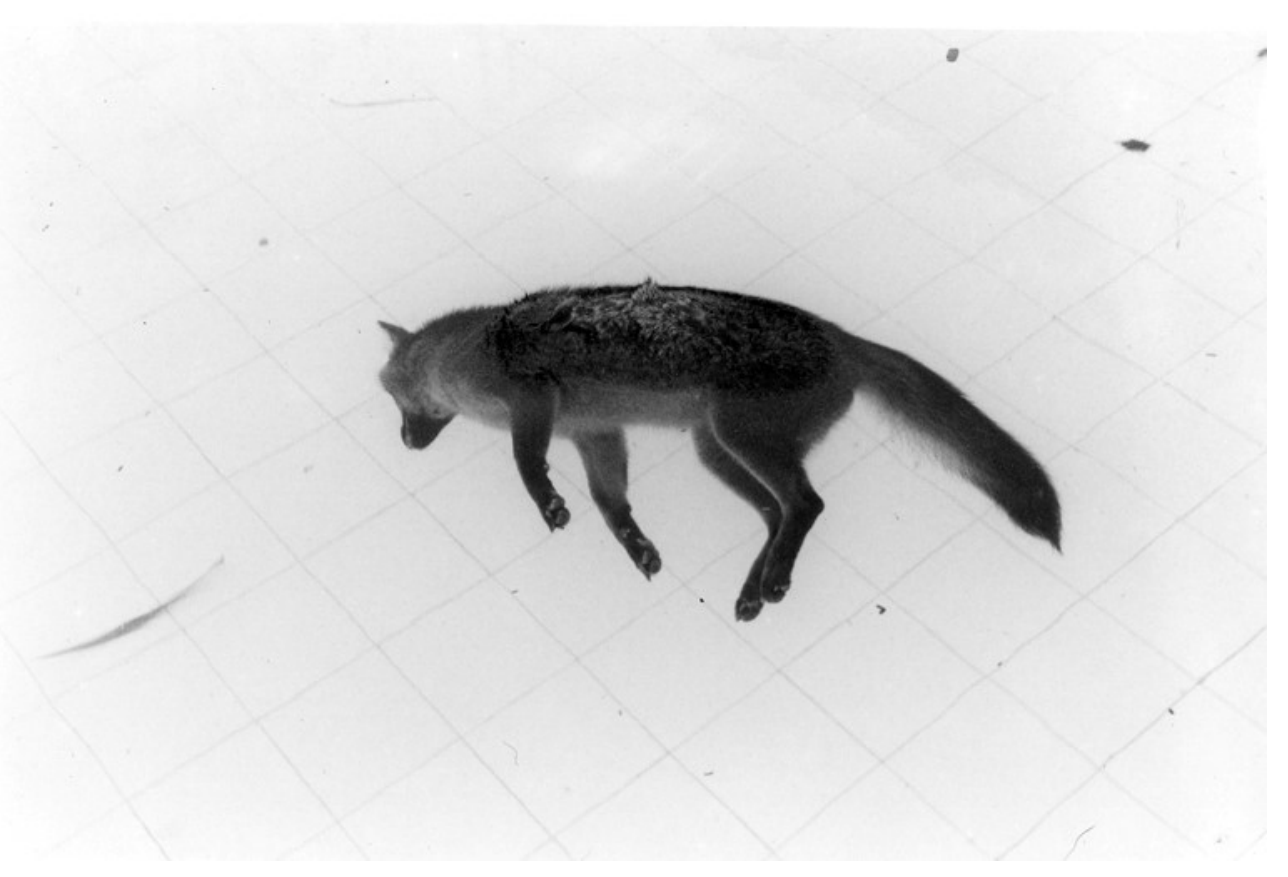

Figura 1 - Julia Amaral, Raposa, 2006 (Créditos: Acervo da artista).

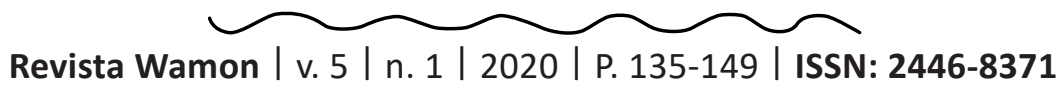


Volto à fotografia, em preto e branco, "Raposa” (2006), vista no decorrer da exposição. O registro parece capturar o instante exato de um corpo cinzento afogado numa piscina seriamente vazia. Aquele resto d'água cobre, quase por completo, a azarada raposa. Ela continua com sua estrutura inteiriça, com a pelagem e patas todas no lugar, porém, por algum mal-entendido, sucumbe entre os azulejos da emboscada imprevisível. As costas das raposas, que apontam sempre para o alto quando perambulam pelas matas - diferente das costas da maioria dos humanos que apontam para o céu apenas quando dormem, morrem ou ficam de bruços - olham para o alto das copas das árvores e caminham em conciliação com as nuvens. Metade das costas da raposa de Amaral estão mergulhadas na poça clórica e a outra metade fica livre. A ambiguidade que consta nessa descrição corrobora com a liberdade que temos perante a morte: alguma possibilidade mínima de seguir buscando horizontes e o enfrentamento concreto que teremos com a velha senhora que erra com sua foice em mãos. A imagem suscitada pela artista - "Ter as costas livres" - encaminha, a meu ver, uma possibilidade de considerar a liberdade como um horizonte a ser vislumbrado. Talvez Amaral exponha sobre uma liberdade que reclama por um corpo desvanecente e que encara a morte como um acontecimento anunciado.

A artista, sobre os seres e os gestos que povoaram o conjunto expositivo, disse: "Talvez os bichos não tenham medo da morte. Nós, muitas vezes, temos. A leveza do corpo da raposa, da imagem que ficou registrada na fotografia parece sobrenatural. Mas de forma nenhuma é sobrenatural, justamente, ela é uma imagem também selvagem", e acrescenta, "Deleuze define o animal como o ser à espreita, um ser, fundamentalmente, à espreita. Nunca está tranquilo. Ele diz que o escritor e o filósofo estão também à espreita. Eu me arrisco a dizer que também os fotógrafos e os artistas" (AMARAL, 2015: s/p).

Estar à espreita pode aventar sobre uma observação com muita atenção, sem cessar, para encontrar alguma coisa ou como uma expressão de autocuidado. A sistemática coleta de animais, como seu posterior registro, ou, ainda, a fundição dos delicados cogumelos, são as tarefas meticulosas realizadas nos processos da artista. Permanecer à espreita, com uma escuta atenta, com uma percepção de alerta, pode oferecer apesar do tom de vigilância que tal expressão carrega - um direcionamento de abertura ao inesperado. Como o encontro eventual com uma raposa afogada. E estar à espreita não pressupõe somente uma reação fria ou de ataque, mas como um fortuito encontro com as alteridades na jornada no mundo. E não seria essa também a atenção requerida em "A queda do céu"? Um encontro com outras formas?

\section{Diálogos cerimoniais e o discurso hereamuu: propostas à escuta dos napë}

O livro, "A queda do céu", é, entre outras coisas, um recado de Davi Kopenawa e Bruce Albert aos napë que insistem em destruir a floresta e todos os seres, vozes e brilhos que nela estão. É em nome da existência no porvir que os autores direcionam suas críticas e argumentações. Suas ações não estão centralizadas na continuidade, única e exclusiva, dos povos indígenas. Pelo contrário, o que Kopenawa e Albert fazem é um movimento que inclui os brancos em uma ação diplomática (KELLY, 2017a) de renovação ao que está sendo arquitetado pelos próprios "povos da mercadoria" ${ }^{33}$. Essas palavras discorrem, por exemplo, sobre a continuidade das vozes dos xamãs reverberarem dentro da floresta: "É por isso que gostaria que os brancos escutassem nossas palavras e pudessem sonhar eles mesmos com tudo isso, porque, se os cantos dos xamãs deixarem de ser ouvidos na floresta, eles não serão mais poupados do que nós" (KOPENAWA; ALBERT, 2015: 491). Sem as vozes dos xamãs, as quais podem ser ouvidas na floresta, nada e nem ninguém poderá permanecer seguro à letal queda do céu.

${ }^{83} \mathrm{O}$ "povo da mercadoria" é uma das formas que Davi Kopenawa se refere aos não-indígenas ao longo da "A queda do céu". Isso está ligado, entre outras coisas, à ganância e ao poder de destruição que os napë direcionam aos povos indígenas e à floresta. 
Esse manifesto espiritual - ou a flecha revestida de renovação direcionada ao peito dos napë - está longe de ter sua autoria restrita aos nomes que assinam a capa da obra. Kopenawa, em diversos trechos, reivindica que as palavras dadas aos napë também pertencem ao seu sogro Lourival, a Omama (o demiurgo), aos xapiri e aos xamãs. Neste sentido, as reflexões estão apoiadas em um caminho de aprendizado com os mais velhos, com seu sogro que administrou a yãkoana (substância inalada pelos xamãs) e, ainda, com os xapiri que descem do céu cantando em espelhos muito brilhantes. Não é à toa que Kopenawa enfatiza o aprendizado em diversos momentos de sua reflexão. Ele mesmo inicia o livro trazendo palavras que guardam justamente esse sentido: "Gosto de explicar essas coisas para os brancos, para eles poderem saber" (KOPENAWA; ALBERT, 2015: 63) ${ }^{84}$.

O pacto (etnográfico) entre Davi Kopenawa e Bruce Albert, entendendo o segundo como um "truchement às avessas" (tradutor com responsabilidades com os povos indígenas), acompanha um exercício que pretende restituir e dar continuidade à vida da floresta ${ }^{85}$. Falar sobre a urihi a solicita uma retomada que apreende também os próprios contextos históricos lançados sobre as memórias do contato. A construção da Rodovia Federal Perimetral Norte (em 1970) e a corrida do ouro (com auge nos anos de 1980) são episódios traumáticos que esfacelaram populações indígenas, contaminaram rios, envenenaram pessoas, chafurdaram solos, tombaram árvores, afugentaram a caça, afastaram os xapiri, cessaram vozes de xamãs, entre tantas outras ações de devastação e violência ${ }^{86}$. "A queda do céu" leva em conta esses episódios de voracidade destrutiva (lembrando que a mineração ilegal de ouro continua sendo realizada intensiva e criminosamente no território yanomami) e anuncia uma nova postura ética em relação à "terra-floresta".

Vale ressaltar que, para os Yanomami, a "terra-floresta" (urihi a) não compreende um domínio exterior à sociedade. Segundo Bruce Albert (2018) "trata-se, ao contrário, de um ser vivo dotado, como os demais de uma imagem-essência (utupë a), que os xamãs chamam de urihinari a" (2018: 106). Quando a floresta tem suas árvores derrubadas ela sente dor - quando queimada ela pode até morrer - e por consequência o Ohinari (espírito da fome) pode instalar-se ali. Como acrescenta o autor: "Diz-se então que a 'floresta tem valor de fome' (urihi a në ohi) e que essa entidade maléfica sopra, dia após dia, seu pó alucinógeno nas narinas dos humanos a fim de enfraquecê-los, para então devorá-los" (ALBERT, 2018: 106). Quando o espírito da fome se instala na floresta os xamãs precisam trabalhar exaustivamente para afastá-lo, por isso Kopenawa direciona essas palavras aos brancos, para interromperem suas ações de destruição e para que a brisa fresca possa voltar a soprar na floresta.

Os diálogos cerimoniais yanomami e o discurso hereamuu aparecem com maior evidência em um subcapítulo do livro, intitulado "Falar aos brancos" (KOPENAWA; ALBERT, 2015: 375-393). Não que os diálogos cerimoniais não sejam também motores da própria forma como Kopenawa escolheu narrar suas palavras. É evidente que os diálogos cerimoniais são matrizes da forma de como falar aos napee, porém, nesse capítulo,

\footnotetext{
${ }^{84}$ Originalmente essa citação pode ser conferida em: “'I Fight Because I Am Alive': An Interview with Davi Kopenawa Yanomami" entrevista de Terence Turner com Davi Kopenawa (1991). Ela também abre o primeiro texto de Davi Kopenawa em "A queda do céu" (2015), o "Palavras dadas" (pp. 63-66), o qual explicita o interesse do xamã pela escrita de um livro.

${ }^{85}$ Consistentes análises e considerações sobre a obra, "A queda do céu", podem ser conferidas em: Kelly (2013); Viveiros de Castro (2015); Schuler Zea (2016); Dias (2017); Krenak (2019) e Limulja (2019).

${ }^{86}$ Tanto a construção da Rodovia Federal Perimetral Norte como a corrida pelo ouro foram registradas em trabalhos fotográficos pela eximia artista Claudia Andujar. Ver mais em: Claudia Andujar: A luta yanomami com a organização de Thyago Nogueira (2018). Mais sobre a mineração ilegal que ocorre no Território Indígena yanomami ver detalhes em: O outro canibal e a queda do céu: Uma crítica xamânica de economia política da natureza (Yanomami) de Bruce Albert (2000).
} 
vemos uma explicação bastante estruturada das diferenciações que perpassam cada diálogo e discurso. Esses diálogos estão associados à falta de sabedoria dos brancos quanto ao dever de proteger a floresta e aparecem logo no início da última parte, denominada como "A queda do céu" (homônima ao livro), a qual possui o tom geral de uma alternativa xamânica de como continuar com um céu seguro. Parece que o autor escolhe trazer as diferenciações, pormenorizadas e atentas, como uma maneira de ensinar tintim por tintim aos brancos. Não saímos das últimas páginas com o "pensamento vazio". Pelo contrário, somos capturados e levados a entender as críticas e alternativas como indicações minuciosas realizadas pelo autor. Espera-se, também aqui, que o conhecimento seja mesmo transformador e que possa ser catalizador de outras práticas quanto aos cuidados da urihi $a$.

O hereamuu é um discurso proferido pelos mais velhos da aldeia - os "grandes homens" (pais e/ou sogros). Esses discursos são extensos e ricos em sabedoria, iniciam antes da alvorada ou no começo da noite, e dizem respeito a conteúdos históricos e mitológicos, ou mesmo a atividades nas roças, as caças e outras atividades econômicas, políticas e cerimoniais. Os mais velhos são capazes de reportar aos mais jovens, ainda "na hora do orvalho" (antes do amanhecer), contando sobre as florestas nas quais seus parentes viveram, sobre a fase da infância e juventude, os aprendizados com seus mestres, as incursões guerreiras, os tempos anteriores aos napë, e muito mais. Os xamãs ficam incumbidos das narrativas mitológicas: contam sobre o tempo dos "animais ancestrais", dos mundos distantes, das casas dos espíritos, e assim por diante. Como os autores explicam: "A raiz do verbo (-here) é também a dos termos que designam os pulmões e os movimentos de respiração" (KOPENAWA; ALBERT, 2015: 664). Assim, para falar como os "grandes homens", é necessário ficar atento aos cantos dos xapiri, ter fôlego, "estudar" com muita dedicação e ser acompanhado por aplicações de yãkoana.

Segundo os autores, "para ser capaz de proferir discursos em hereamuu com firmeza, é preciso conseguir a imagem do gavião kãokãoma, que tem voz potente, chamamo-la Kãomari” (KOPENAWA; ALBERT, 2015: 381$)^{87}$. É imprescindível a transformação do corpo daquele que profere os discursos hereamuน ${ }^{88}$, porque para esses discursos é necessária uma boca que não demonstre vergonha, uma garganta capaz de proferir palavras com agilidade e que não se percam, um peito limpo para ser a morada dos xapiri, uma língua firme e sem ressecamento, entre outras modificações. É só assim que as palavras podem ter vigor e firmeza.

O hereamuu, conforme explica Carvalho (2013) em pesquisas realizadas junto aos Yanomami da região do Toototopi, é um dos mecanismos mais significantes para ensinar os jovens. Ele é proferido pelos que possuem um talento oratório excepcional - aqueles que "sabem muito" (thai mahiowi) - e podem ainda garantir certa "perpetuação da tradição indígena" (CARVALHO, 2013: 70), pois esse diálogo é capaz de articular os tempos imemoriais - junto do passado mítico - produzindo ressignificações no presente. A autora manifesta que o "hereamuu diário" é proferido entre os co-residentes acompanhado das tarefas cotidianas: "Deitados em suas redes, ou se alimentando - nos horários de suas principais refeições -, ninguém para seus afazeres para prestar atenção às falas do pata" (idem). Já o "hereamuu inter-aldeão" versa sobre a educação, a saúde e as associações - possui um fundo mais político e é realizado em espaços públicos comunais.

Wayaтuи, yãimuи e o hiimuu são tipos de diálogos cerimoniais. Diferente do discurso hereamuu, os jovens também podem proferi-los. No entanto, necessitam do mesmo modo acompanhar uma série de prerrogativas. Geralmente, os diálogos wayamuu são realizados durante o reahu - festa intercomunitária em que acontecem cerimônias de aliança política e rituais funerários - onde anfitriões e convidados cantam na praça central, em duplas na maioria das vezes, um diante do outro, com a postura ereta (KOPENAWA, ALBERT, 2015; KELLY, 2017a). Os rapazes começam a cantar e, aos poucos, vão sendo substituídos pelos

${ }^{87}$ Ver mais sobre pássaros e cantos em: On Yanomami ceremonial dialogues: a political aesthetic of metaphorical agency de José Kelly (2017a, p. 189).

${ }^{88}$ O capítulo da “A queda do céu” (2015), “Devir outro” (pp. 69-217), exibe valiosas reflexões sobre o corpo e as transformações. 
mais experientes. Esses diálogos versam sobre as desavenças e rivalidades entre aldeias, dos duplos feridos, das moléstias sofridas, das feitiçarias, entre outras coisas.

Para Kelly (2017b) "o wayamou é um gênero de fala reconhecida, marcado pela alta densidade metafórica, a força e a rapidez das falas. O virtuosismo deste gênero oratório se obtém com a prática”, e prossegue, "mas requer também capacidade onírica de sonhar distante para, durante o diálogo, poder nomear lugares afastados, relatar fragmentos míticos e históricos, assim como adquirir loquacidade verbal" (2017: 709). O autor sugere o entrelaçamento entre a prática da oratória e as longas viagens oníricas. Porém, essas recomendações estão longe daquilo que Kopenawa diz sobre os brancos, afirmando que não sabemos escutar, falamos como "fantasmas" e não sonhamos muito distante. Diante disso, destaco os diálogos cerimoniais e sonhos como uma alternativa, um caminho a ser vislumbrado pelos napë como um contraponto à destruição da floresta e à falta de sabedoria ${ }^{89}$.

Quando um participante conduz um diálogo wayamuu, o outro participante responde seu canto com as mesmas palavras ou apresenta uma nova fala com pequenas variações (Kelly, 2017a). Como observa o autor em sua minuciosa análise:

A resposta tem que ser rápida, na medida em que às vezes um interlocutor adivinha a frase do participante antes de terminar. A voz - falada ou cantada - geralmente é muito vigorosa, muitas vezes intimidadora, enquanto o falante harmoniza suas palavras com o leve balançar de seu corpo e o bater de suas mãos nas pernas agachadas, pontuando a força de suas palavras. Ele também pode estar de pé, movendo-se de um lado para o outro, de frente para seu adversário, possivelmente brandindo seu arco e flecha. O respondente deve repetir as palavras do interlocutor, mesmo que o que é dito seja uma recriminação; ele pode às vezes apenas reconhecer a legitimidade das palavras do participante. Ele pode repetir frase por frase, ou sílaba por sílaba, dependendo do formato da condução, ou aguardar uma sequência multissilábica separada para terminar e então proferir a frase reconstruída. Às vezes, uma resposta espirituosa pode, por algumas frases, mudar a direção da troca para o respondente, mas em geral a convenção é que, depois que o participante terminar, será sua vez de ouvir e repetir as palavras de seu interlocutor (Ibidem: 181. Tradução minha) ${ }^{90}$.

Após o fim do wayamuu, convidados e anfitriões começam outro diálogo durante a noite - o yãimuu -, que exige que se formem duplas e que os participantes se agachem e que cantem muito próximos uns dos outros ${ }^{11}$. Em "A queda do céu" os autores afirmam: "As palavras de yãimuu são próximas e mais inteligentes. Penetram fundo dentro de nós [...]. Quando os grandes homens querem mesmo conversar e pôr fim às brigas que os opõem, usam o yãimuu" (KOPENAWA; ALBERT, 2015: 377). Esses diálogos podem

\footnotetext{
${ }^{89}$ Ver direções próximas em: Aprendendo sobre os diálogos cerimoniais Yanomami de José Kelly (2015).

90 "The response has to be fast, to the extent that sometimes an interlocutor guesses the lead's phrase before he finishes. The voice - spoken or chanted - is usually very vigorous, often intimidating, as the speaker harmonizes his words with the slight swinging of his body and the slapping of his hands on his crouched legs, punctuating the force of his words. He may also be standing up, moving side to side facing his contender, perhaps brandishing his bow and arrow. The respondent must repeat the words of the lead, even if what is said is a recrimination; he may at times just acknowledge the rightfulness of the lead's words. He may repeat phrase by phrase, or syllable by syllable, depending on the lead's format, or await a separated multi-syllable sequence to end and then utter the reconstructed phrase. At times, a witty response may, for a few phrases, switch the lead of the exchange to the respondent, but in general the convention is that after the lead has finished, it will be his turn to listen and repeat the words of his interlocutor" (KELLY, 2017a: 181).

${ }^{91}$ Para José Kelly (2019), em pesquisas realizadas junto aos Yanomami do Alto Orinoco, as diferenciações entre o yãłmuu e o wayamuu não são tão marcadas como aquelas narradas por Davi Kopenawa e Bruce Albert (2015). Informação pessoal (02 de setembro de 2019).
} 
também intermediar pedidos por mercadorias, por uma possível esposa e por responsabilidades com seu futuro sogro. Assim, é possível entender o yãimuu como uma forma de "diplomacia" (SZTUTMAN, 2019).

Como explica o xamã e intelectual quando relata sobre uma provável cena de rivalidade entre indígenas Yanomami de diferentes aldeias: "Esqueça essas palavras tortas! Continuemos amigos! Minhas reais palavras são belas! Não dê ouvidos àquelas que essa gente de longe tornou outras! São mentirosos!" (KOPENAWA; ALBERT, 2015: 377). Como alternativa aos conflitos algum convidado pode proferir: "Bem! Eis aí uma fala direita mesmo. Não quero mais escutar essas palavras feias, que nos fariam dar bordunadas na cabeça ou flechadas uns nos outros! Sejamos amigos!” (Idem) ${ }^{92}$.

Essa ação diplomática, segundo Sztutman (2019), "constitui-se no trânsito entre mundos e no uso estratégico e cauteloso da linguagem" (2019: s/p). A diplomacia conferida nas festas reahu, nos seus diálogos cerimoniais e nos discursos hereamuu é também entremeada em "A queda do céu" como uma sofisticada forma de apresentar o mundo yanomami ao mundo dos napë. Viveiros de Castro (2015: 39), chamando a atenção para os tratados, as traduções e as negociações acordadas na obra, acentua dizendo que "A queda do céu" é um "documento exemplarmente diplomático" e uma "performance cosmopolítica" ou "cósmico-diplomática". Assim, a forma encontrada para levar aos não-indígenas tais reflexões apresentadas em "A queda do céu" não estão separadas de como são proferidos os diálogos e os discursos no próprio contexto aldeão, pois a diplomacia é inerente à forma como são travados tais diálogos e discursos.

Por fim, rapidamente, o hiimuu não entrou no capítulo "Falar aos brancos", mas também é considerado um diálogo cerimonial. Os autores explicam: "[Ele é] realizado para convidar os membros de uma casa aliada a uma festa reahu ou a virem se juntar a uma incursão bélica e, também, para pedir a um afim potencial que realize o enterro das cinzas funerárias" (KOPENAWA; ALBERT, 2015: 625). Resumidamente, pode-se dizer que o hiimuu possui as características de um diálogo cerimonial de convite.

"Nomear a floresta" (urifi ã wëyëi) aproxima os sonhos, os diálogos cerimoniais e o discurso hereamuи em uma correspondência estreita, provoca Kelly (2017a). Para tanto, o encontro com a "árvore das canções" (amoa hii) em sonhos, a qual era frequentemente visitada pelos ancestrais yanomami no tempo mítico, pode garantir hoje competência aos que cantam em wayamuu. $\mathrm{O}$ autor acrescenta ainda que, no tempo mítico, a "árvore das canções" emanava belas melodias que eram desconhecidas até o momento do encontro (também sonoro) com a amoa hii. O autor realça que quem não sonha com os espíritos dos pássaros, com as paisagens distantes e com a própria "árvore das canções" estará "impróprio para o wayamuu" (Ibidem: 196).

A motivo de exemplo, os Warlpiri, segundo as pesquisas de Glowczewski (2015), falam em público sobre seus sonhos logo que acordam. O sonho é algo trabalhado desde que se é pequeno, pois as pessoas contam a respeito dos seus sonhos a partir das conversas, fazendo movimentos com as mãos, criando desenhos na areia, etc. Essas narrativas são compartilhadas publicamente e as crianças as ouvem. E é no sonho e no compartilhamento dele que se conhece locais nunca antes vistos. Os sonhares são itinerários míticos exaustivamente longos que podem fazer com que o território seja profundamente percorrido. Neste sentido, os itinerários nômades (segundo a autora alguns Warlpiri, hoje, por razões de conflitos de territoriais, são sedentários, mas mesmo assim caminham muito em seus sonhos) combinados às viagens em sonhos fazem uma superposição do "imaginário" e do "real". Glowczewski chama a atenção para um modo reticu-

\footnotetext{
92 Para conferir outro relato de como o yãimuu pode intermediar conflitos, ver em: Kopenawa; Albert, 2015: 451-452.
} 
lar de pensar - o qual abandona uma visão analógica do mundo (que prescreve um mundo essencialmente dualista) - por "metamorfoses conceituais e materialmente constantes" (Ibidem: 33).

Quando Kelly (2017a) apresenta o urifi ã wëyëi, ele também diz que as viagens em sonhos são experiências importantes que capacitam e proporcionam conhecimento para nomear a floresta (além de ajudarem na caça e no xamanismo). "Não é suficiente, então, enumerar os lugares de que se tem notícia, meus colegas insistem; é preciso vê-los próximos em sonhos, para conhecê-los e nomeá-los durante o wayamou" (KELLY, 2017a: 190. Tradução minha) ${ }^{93}$, arremata o autor. A propósito, Kelly enfatiza que esse entendimento sobre a floresta não se restringe a pensá-la como um "pedaço de natureza", mas, de fato, "como uma conjunção territorializada de presenças humanas e espirituais específicas, cujo resultado é um lugar com dadas características" (Ibidem, p. 196. Tradução minha) ${ }^{94}$.

Novamente, os sonhares para os Warlpiri são descritos como itinerários totêmicos que abarcam uma infinidade de elementos da materialidade do mundo (se contrapondo a certa ideia de "animismo" e encaminhando a noção de "vitalismo" - algo que pode ser aproximado às "imagens-vitais" sugeridas por Kopenawa e Albert [2015]). Eles possuem songlines (rastros de cantos), narrativas, "imagens-forças" e trilhas geográficas míticas, e apontam para as características do próprio território desértico: nascentes, colinas ou rochas. Glowczewski (2015) é enfática ao dizer: "Um Aborígene não diz que um território lhe pertence, mas que ele pertence ao território. Um território não se ocupa, a terra não está para ser conquistada, ela dá sentido aos povos" (2015: 51). Assim, sonhos e cantos recobrem o que a autora expõe sobre os longos itinerários dos sonhares - longe da noção Ocidental de propriedade (posse), o território confere aos povos pertencimento e versa também sobre as experiências desses sujeitos.

O discurso hereamuu e os diálogos cerimoniais em um primeiro momento podem remeter, exclusivamente, a uma competência que se dá a partir de uma oratória vigorosa. Isto é verdade, mas também, seguindo os argumentos desenvolvidos até o momento, é possível entendê-los como uma refinada e atenta prática da escuta. As garantias de falar bem e firme, ter muito conhecimento e enumerar algumas características da floresta são combinadas em uma apurada atenção aos cantos da "árvore das canções" (amoa hii), dos espíritos dos pássaros, dos próprios cantos dos mais virtuosos, entre outras. Saber ouvir, sonhar e falar potencializa um conhecimento que se dá em torno da atenção. E na mesma direção confirma ouvidos atentos, sonhos distantes e cantos fortes.

A combinação desses sentidos e experiências - longe do encarceramento das mesmas em determinados nichos (aos modos das reflexões Ingold, 2011 [2015]) - corrobora com um agir no mundo que se dá na potencialização de diferentes aspectos. Carvalho (2013), por exemplo, demonstra que os Yanomami da região do Toototopi enumeram quatro níveis de conhecimentos: "thai waisipi mahiowi (sabe muito pouco), thai waisipiwi (sabe um pouco), thai hathoho (sabe mais ou menos) e thai mahi (sabe muito)" (2013: 70). A eloquência nos diálogos cerimoniais - atrelada ao nível de conhecimento da pessoa - não é fortificada, até onde entendo, apenas sob o viés de uma fala vigorosa. Longe disso, arrisco-me a dizer que o próprio vigor da fala engaja as longas viagens oníricas, prolongados exercícios de escuta dos "grandes homens", uma exaustiva jornada pelos conhecimentos sobre a floresta, e assim por diante, em um caminho que determina uma enorme atenção e trabalhos intensos.

À vista disso retomo uma fala poderosa de Kopenawa: "Quem não bebe o sopro dos espíritos tem o pensamento curto e enfumaçado; quem não é olhado pelos xapiripë não sonha, só dorme como um

\footnotetext{
93 "It is not enough, then, to recite places one has heard about, my colleagues insist; one must see them close in dreams, to know and then name them during wayamou" (KELLY, 2017a: 190).

94 "as a territorialized conjunction of specific human and spiritual presences, the outcome of which is a place with given characteristics" (KELLY, 2017a: 196).
} 
machado no chão" (2000: 19). Essas palavras podem encaminhar a via de mão dupla do encontro com os espíritos da floresta: não é só a pessoa que precisa ver os xapiri em uma iniciação xamânica, mas também os próprios espíritos precisam ver o iniciado. Isso corrobora com o que venho dissertando até o momento, já que cantar como os xapiri demanda também um retorno dos mesmos. Assim o conhecimento para os diálogos cerimoniais, principalmente aqueles destacados por Kelly (2017a) no contexto do wayamuu, exige certa ecologia entre os espíritos, cantos, escutas, sonhos, odores, entre outros.

Essa ecologia das relações pode aguçar outras ações éticas com a floresta. Se Kopenawa tem como interesse ter suas palavras lidas e escutadas pela grande maioria dos brancos, para que estanquemos o chafurdamento do solo à procura de ouro e ainda cessemos a derrubada de árvores; trazer os discursos, os diálogos cerimoniais e os sonhos a contrapelo da leitura crítica da obra dirige um movimento de salvaguarda do brilho dos xapiri, das canções dos xamãs, da brisa fresca que sopra na floresta, da caça abundante, e assim por diante. Pois manter a floresta de pé demanda um trabalho intenso dos xamãs que convocam seus xapiri a restituírem a integridade da urihi a. Os xapiri podem fugir caso sejam espantados pelas epidemias e as fumaças provocadas pelos napë. Próximo dessas reflexões lembro-me de uma legenda de Joseca Yanomami (2015) que acompanha uma de suas ilustrações: "Ainda que os garimpeiros espalhem muita sujeira na floresta, os espíritos a limpam, voltando assim a aparecer ali suas clareiras, suas braçadeiras de pena de arara, suas penugens brancas e seus ornamentos feitos com pequenos pássaros coloridos" (YANOMAMI: 214 apud PEDROSA; SCHWARCZ, 2015). No entanto, como salienta Kopenawa, caso os napë não parem de destruir a floresta, os cantos dos xapiri serão definitivamente calados, e, como contrapartida, o céu cairá.

Certamente o hereamuu requer uma escuta atenta dos mais jovens, pois somente os mais virtuosos (leia-se também os mais velhos) são capazes de proferi-lo. Kopenawa, até o momento da produção do livro, disse não estar totalmente preparado para falar em hereamuu ${ }^{95}$. A atenção a esse discurso pode orientar uma direção altamente relevante aos napë: uma pausa diante dos mais velhos e daqueles que são detentores da sabedoria. Próximo disso, o wayamuи e о yãimuи apresentam características de diplomacia e de resolução de conflitos, são formas com as quais os indígenas Yanomami manejam conflitos e restabelecem ordens. Com certeza sonhos mais longos poderiam ser desvelados - para nós, brancos - caso soubéssemos agir e ouvir como aos modos de fazer diálogo cerimonial e discursar em hereamuu.

\section{[Pausa \#2: As mãos negativas]}

$\begin{aligned} \text { A face do oceano } & \text { O homem estava só na gruta } \\ \text { sob a falésia } & \text { à face do oceano } \\ \text { sobre a parede de granito } & \text { Todas as mãos têm o mesmo tamanho } \\ \text { estas mãos } & \text { estava só } \\ \text { abertas } & \text { O homem sozinho na gruta olhou } \\ \text { Azuis } & \text { no marulho } \\ \text { E negras } & \text { no marulho do mar } \\ \text { Do azul da água } & \text { a imensidão das coisas } \\ \text { Do negro da noite } & \begin{array}{l}\text { Egritou } \\ \end{array} \\ & \text { (Marguerite Duras, 1979) }\end{aligned}$

As palavras acima compõem o poema "As mãos negativas", de Marguerite Duras. Pude ouvi-las ecoando no chão de uma exposição, "A mão negativa" (para a ocasião o curador escolhera eliminar o plural), durante uma visita ao Parque Lage $(\mathrm{RJ})^{97}$. Sobre um piso de mármore, em uma TV de plasma, os

\footnotetext{
96 Poema traduzido por Paulo de Andrade (2009).
} 
versos foram acolhidos por uma filmagem que tinha como mote um passeio pelas ruas de uma grande cidade do anoitecer até o início do dia. O rearranjo do poema com as imagens é fruto da imersão de Duras também pelas produções audiovisuais (ver Figura 2).

A proposta de Duras incita um diálogo - com uma permissão poética que desestabiliza fronteiras de tempo e espaço - com um homem do paleolítico superior que pintou suas mãos na parede de uma gruta trinta mil anos atrás. Mãos negativas são as pinturas encontradas, em tons de azul, negro e às vezes em vermelho, na Caverna de Gargas (Europa do Atlântico Sul). Essas mãos sempre postas abertas, com diferentes tamanhos, se espalham pelas paredes de granito com o anseio pela comunicação com outrem. Algumas delas reverberam nos versos da autora e clamam por uma escuta até hoje.

Uma voz incute ilustrações sobre o cenário de onde essas mãos foram encontradas e traz à cena um homem solitário que grita em busca de qualquer ouvinte. Seu clamor percorre o tempo e repercute nos ouvidos de um eu lírico. Talvez alguma arqueóloga responsável pelas pesquisas em Gargas? Os endereçados dessa escuta são inúmeros, mas o clamor ainda assim atravessa gerações (Duras, 1979: s/p):

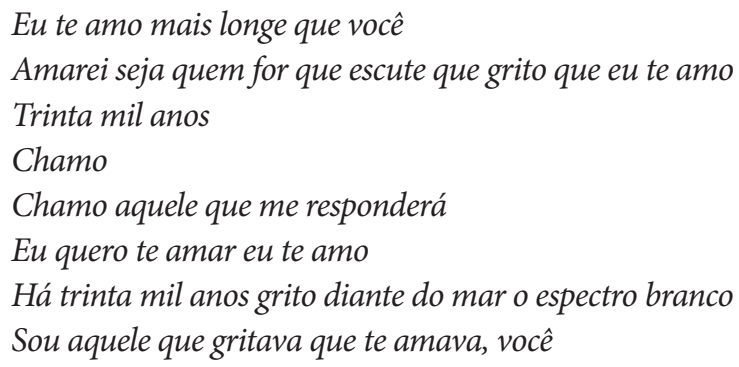

A exposição, onde pude ouvir essas palavras, tinha como um de seus principais eixos narrativos uma proposta de elaboração imaginativa em tempos de retrocessos, catástrofes climáticas e crimes ambientais. O curador, Bernardo José de Souza, à época, disse: "Aqueles que sobreviveram à grande onda no verão de 2074, mal puderam fazer face, no ano seguinte, às tórridas temperaturas que assolaram capivaras, macacos e homens sem fazer distinção" (2015: s/p). E avança: "Jamais houve notícia, por esses costados, de tamanha e irremediável calamidade pública: um êxodo urbano sem precedentes, atroz; sequer Graciliano Ramos ousaria especular coisa igual" (Idem).

O arranjo expositivo que apontava para uma perspectiva de fim do mundo, próxima à ausência de qualquer horizonte no porvir, lidava com o estabelecimento de algum fio que pudesse retomar os traumas do passado, projetar alguma possibilidade no futuro, diante de um presente consolidado por uma realidade extremamente frágil e incerta. Como enfatizou Souza (2015) sobre uma alternativa ao momento que nos compreende: "[as zonas de contraste e discrepâncias] nos demanda olhar para o passado mediante a revisão histórica, e projetar o futuro sobre bases tão precárias e provisórias quanto a nossa capacidade de articular conceitualmente o período em que vivemos" ( $\mathrm{s} / \mathrm{p})$.

Apesar das fictícias altas temperaturas, das mortes de humanos e animais, da aridez que deflagrou florestas, a exposição tentou travar algum diálogo - junto da licença literária adicionada ao arranjo - com um ser qualquer que escutasse por seu clamor. A insistência pelo desejo de uma escuta - endereçada a ouvidos atentos - é a aspiração da narrativa expositiva, pois a necessidade de uma escuta por vir dá alguma anuência para um futuro possível. A escuta continuará sendo possível? Existirão ouvidos atentos à fala desse homem

\footnotetext{
${ }^{97}$ Outras informações sobre a exposição podem ser consultadas no acervo online da Escola de Artes Visuais do Parque Lage: http://acervo.memorialage.com.br/xmlui /search?order=DESC\&rpp=10\&sort_by=score\&page=1\&group_by=none\&etal=0\&view=listing\&fq=A\%20mão\%20negativa Acesso em: 30 de julho de 2019
} 


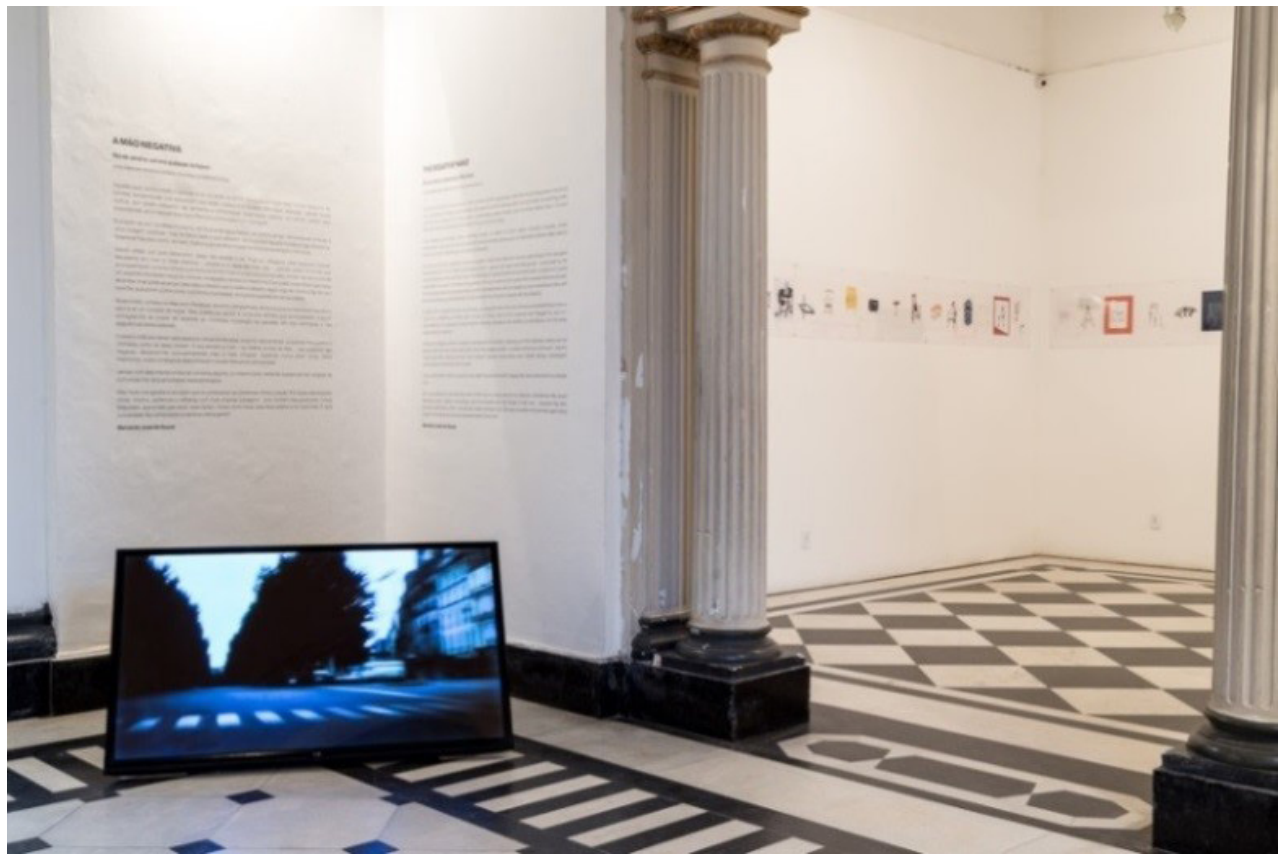

Figura 2 - Vista da exposição, “A mão negativa” (2015), com curadoria de Bernardo José de Souza, no Parque Lage. No canto da imagem é possível ver a TV que exibia o filme-poema de Marguerite Duras (Créditos: Pedro Agilson).

da Gruta de Gargas? E para quais seres do século XXI? Chamo aquele que me responderá [...] Há trinta mil anos grito diante do mar o espectro branco. Sou aquele que gritava que te amava (DURAS, 1979: s/p).

O título do comentário crítico de Peter Gow (2014), a respeito da "A queda do céu", baseado nas palavras do próprio autor Yanomami, é assertivo nesse quesito: "Listen to me, listen to me, listen to me, listen to me..." ("Escutem-me, escutem-me, escutem-me..."). Neste sentido, quais ouvidos se mostram atentos ao que Davi Kopenawa tem a dizer? E, ainda, qual atenção é dedicada aos cantos dos xapiri? Tais perguntas não param de ressoar nas "palavras dadas" aos brancos.

\section{Alternativas xamânicas à queda do céu}

Sztutman (2019) recomenda a leitura do livro "A queda do céu" como "em wayamuu" ou "em yãimuu". Os diálogos cerimoniais e os discursos alcançam as "peles de papel"98 e nessa obra se tornam as próprias "palavras dadas" aos brancos. Diversos autores e autoras mostraram como as artes indígenas seja a literatura, o grafismo, a cerâmica, as artes verbais, os mitos, a música, a pintura corporal, etc. - não estão restritas às superfícies que as expressam (CARNEIRO DA CUNHA, 1998; SEVERI, 2014 [2017]; HUGH-JONES, 2015, entre tantos outros). Cantos são capazes de dar a ver grafismos, literatura chama por diálogos rituais, mitos podem ser tecidos em algodão ou ganhar forma com pincéis sobre a cerâmica, $\mathrm{e}$ os movimentos são sempre crescentes. Por isso o recado de Davi Kopenawa pode ser lido nesse sentido e, ainda, é capaz de ser entendido como uma performance ao modo do wayamuu e do yãimuu. Assim o líder indígena canta aos napë, com bravura e firmeza, sua alternativa de reconciliação com o céu.

Junto a essa intertextualidade e "interdiscursividade" (SZTUTMAN, 2019) da maneira de Kopenawa se reportar aos não-indígenas, uma singular forma de escuta é tratada ${ }^{99}$ ao longo das páginas da

${ }^{98}$ Brevemente - deixando as explicações mais sofisticadas a cargo de Albert (2015: 610) -, as "peles de papel" podem ser entendidas nesse primeiro momento como uma forma yanomami de se reportar às folhas de papel de livros, cadernos, jornais, documentos, entre outros. Para outros casos, ver mais em: Escrita nas pedras, escrita no papel de Stephen Hugh-Jones (2015). 
"A queda do céu". Amarrar o céu com firmeza demanda uma escuta atenta às palavras ditas pelo xamã e intelectual indígena. Essas palavras são minuciosamente trabalhadas para que outras escutas possam ser mobilizadas e tratam, justamente, de encaminhar uma nova postura na relação com os povos indígenas e com a floresta - contrária às formas vorazes e destrutivas dos napë.

As formas de escuta já foram tratadas até aqui. Tentei demonstrar, seguindo os diálogos cerimoniais e o discurso hereamuu, que as especificidades dessas formas de falar e escutar acionam certa relação entre esses próprios elementos - a associação direta entre escuta e fala - e que chamam os sonhos, por exemplo, para que os conhecimentos sobre a floresta possam ser aprofundados. Vimos que ser virtuoso nos diálogos e discursos demanda uma grande esperteza sobre os saberes em relação à floresta, e esses conhecimentos podem ser ainda apreendidos nas longas viagens em sonhos e com o encontro com a "árvore das canções" (amoa hii).

Não é à toa a \#Pausa 1 neste ensaio, pois a sugestão do 'artista à espreita' (premissa cara à artista $\mathrm{e}$ constitutiva de seus projetos artísticos) alicerça a presença das escutas e dos diálogos forjados no decorrer dos encontros (ver Figura 1). Da mesma forma, a reverberação, lá na \#Pausa 2, do poema de Duras - com seu deslocamento de tempo e espaço -, apresenta um clamor que ultrapassa horizontes e ressoa em uma sala de exposição de arte (ver Figura 2). Essas Pausas, costuradas junto às palavras de Davi Kopenawa e Bruce Albert, suscitam uma atenção aos seus ensinamentos e apontam para certo aprendizado e aperfeiçoamento da atenção a outras ontologias.

Kopenawa é bastante enfático quando diz que as palavras com que ele se comunica com os napë não pertencem somente a ele: elas também pertencem ao seu sogro Lourival, a Omama (o demiurgo), aos xapiri e aos xamãs. Esse é um aspecto muito significativo quando atravessado às formas dos não-indígenas, pois no "mundo dos brancos" a questão entraria na seara estritamente da propriedade e da posse. Como é que se escuta diante dessas múltiplas escutas? Como escutar na escuta? Ainda, como travar uma escuta em escuta?

Ora, foi a partir dessas reflexões que Kopenawa e Albert encararam as diferenciações entre os napë e os povos indígenas, no livro "A queda do céu", elencando uma série de divergências nos modos de falar, escutar, sonhar, lidar com a floresta, entre outros. Eles apontaram, a todo o momento, para certo entrelaçamento de todos esses elementos. Como disse anteriormente, entendo que saber escutar tem a ver também com uma fala vigorosa, uma experiência em sonho, com conhecimentos mais primorosos sobre a floresta, e assim por diante. Como saber falar, similarmente, percorre também o caminho colocado previamente: do escutar, da distância dos sonhos e da destreza sobre a floresta. Por isso acredito que todas as explicações primorosas de Kopenawa não são à toa. $\mathrm{O}$ xamã adota grandes parágrafos, longas narrativas, exímias descrições, subcapítulos inteiros do livro com o objetivo de trazer à tona os pormenores do que são essas formas yanomami de relação com o planeta.

\section{Agradecimentos}

Quero agradecer ao professor José Kelly pelas orientações e as importantes trocas durante essa pesquisa. Suas leituras e comentários foram fundamentais para resolver os mal-entendidos do texto. A Julia Amaral e Pedro Agilson por compartilharem comigo suas belas fotografias. Ao amigo, Alexsander Brandão, pela leitura cuidadosa. Ao amigo, Lino Gabriel Nascimento dos Santos, pela a ajuda com o abstract. A amiga, Camila Horbatiuk Dutra, pelas contribuições ao texto. Foi na disciplina de Etnologia Indígena (UFSC) onde conheci "A queda do céu". Agradeço à professora, Evelyn Schuler Zea, pelas aulas e

\footnotetext{
${ }^{99}$ Sobre "tratados" e as traduções ver mais em: Tradução como iniciação de Evelyn Schuler Zea (2016) e no Tratado do ter a ver: notas a partir de motivos visuais Waiwai de Evelyn Schuler Zea e Alfredo Zea (2017).
} 
por ter me apresentado essa magnífica obra. Lembro-me das trocas com xs colegas dessa disciplina e os aprendizados que se desenrolaram nesses encontros. Reconheço também os trabalhos artísticos de Joseca Yanomami e sua palestra no MASP como impulsionadoras dessa pesquisa. Agradeço, por fim, a Davi Kopenawa por todas as palavras que deu aos napë em seu livro. Sinto-me presenteado com tamanha sabedoria. Quero agradecê-lo, mais uma vez, por ter vindo à Universidade Federal de Santa Catarina (UFSC), em uma Jornada de estudantes de Antropologia da qual fiz parte, e por nos ter doado generosas reflexões e horizontes naquela ocasião.

\section{Referências}

ALBERT, Bruce. 2000. O outro canibal e a queda do céu: Uma crítica xamânica de economia política da natureza (Yanomami). In: ALBERT, Bruce. RAMOS, Alcida. (orgs.) Pacificando o branco: cosmologias do contato no norte-amazônico. São Paulo: Editora da UNESP. p. 239-274.

ALBERT, Bruce. 2018. Um mundo cujo nome é floresta. Homenagem a Napëyoma. In: NOGUEIRA, Thyago. (org.). Claudia Andujar: a luta yanomami. São Paulo: Instituto Moreira Salles. p. 102-111.

Brô MC’s. 2010. Eju Orendive. (3m35s). Canal: CUFATVDDOS. Disponível em: https://www.youtube.com/ watch?v=oLbhGYfDmQg. Acesso em: 23 de julho de 2019.

CARNEIRO DA CUNHA, Manuela. 1998. "Pontos de vista sobre a floresta amazônica: xamanismo e tradução". Mana v. 4, n. 1: 7-22.

CARVALHO. Maria Auxiliadora Lima de. 2013. "A dinâmica sociopolítica yanomami no contexto de criação da Hutukara: pata thëpë e a emergência de jovens lideranças políticas”. Textosఓ Debates, Boa Vista n. 20: 64-80.

DIAS, Jamille Pinheiro. 2017. Peles de papel: Caminhos da tradução poética das artes verbais ameríndias. São Paulo-SP. Tese de doutorado em Estudos Linguísticos e Literários em Inglês, Universidade de São Paulo.

DURAS, Marguerite. 1979. As mãos negativas. In: Suplemento. Belo Horizonte, fevereiro de 2009, n. 1317, Secretaria de Estado de Cultura de Minas Gerais. Tradução de Paulo de Andrade. p. 10-11.

GLOWCZEWSKI, Barbara. 2015. Devires totêmicos: cosmopolítica do sonho. Tradução: Jamille Pinheiro Dias. Colaboração de Abrahão de Oliveira Santos. São Paulo: n-1 Edições. Edição bilíngue.

GOW, Peter. 2014. "Listen to me, listen to me, listen to me, listen to me...": A brief commentary on The falling sky by Davi Kopenawa and Bruce Albert. HAU: Journal of Ethnographic Theory v. 4, n. 2: 301-309.

HUGH-JONES, Stephen. 2015. Escrita nas pedras, escrita no papel. In: FAUSTO, Carlos; SEVERI, Carlo. Palavras em imagens - escritas, corpos e memórias. Marseille: Open Edition Press. p. 57-85.

INGOLD, Tim. 2011 [2015]. Estar vivo: ensaios sobre movimento, conhecimento e descrição. Petrópolis: Editora Vozes.

KELLY, José. 2013. KOPENAWA, Davi \& ALBERT, Bruce. La chute du ciel: paroles d'un chaman yanomami. São Carlos: Revista de Antropologia da UFSCar n. 1, v. 5: 172-187.

2015. “Aprendendo sobre os diálogos cerimoniais Yanomami”. SPECIES - Núcleo de Antropologia Especulativa n. 1: 45-65. 
2017a. "On Yanomami ceremonial dialogues: a political aesthetic of metaphorical agency". Journal de la Société des Américanistes v. 103: 179-214.

. 2017b. "Articulação de sistemas médicos, diálogos cerimoniais e reuniões políticas: comentários sobre a antimestiçagem cosmopolítica para além do interétnico". Amazônica: Revista de Antropologia v. 9: 700-715.

KOPENAWA, Davi. 2000. Sonhos das origens. In: RICARDO, Carlos Alberto (Ed.). Povos Indígenas no Brasil (1996-2000). São Paulo, ISA. p. 19-23.

KOPENAWA, Davi; ALBERT, Bruce. 2010 [2015]. A queda do céu: palavras de um xamã yanomami. São Paulo: Companhia das Letras.

2013. The Falling Sky: Words of a Yanomami Shaman. Cambridge, MA: Belknap.

LIMULJA, Hanna Cibele Lins Rocha. 2019. O desejo dos outros: uma etnografia dos sonhos yanomami (pya $u$ - Toototopi). Tese de doutorado em Antropologia Social, Universidade Federal de Santa Catarina.

Julia Amaral - "Ter as costas livres". 2015. Site institucional. Arquivo on-line. Exposições temporárias do Museu Victor Meirelles.

PEDROSA, Adriano; SCHWARCZ, Lilia. 2015. Histórias Mestiças. Catálogo. Rio de Janeiro: Cobogó.

NOGUEIRA, Thyago. (org.). 2018. Claudia Andujar: a luta yanomami. São Paulo: Instituto Moreira Salles.

SEVERI, Carlo. 2014 [2017]. "Seres transmutantes: uma proposta para uma antropologia do pensamento". Ilha Revista de Antropologia v. 19, n. 1: 217-262.

SCHULER ZEA, Evelyn. 2016. “Tradução como iniciação”. Cadernos de tradução v. 36: 192-212.

SCHULER ZEA, Evelyn; ZEA, Alfredo. 2017. Tratado do ter a ver: notas a partir de motivos visuais Waiwai. Climacom Cultura Científica - Pesquisa, Jornalismo e Arte, v. 10: 119-123.

SOUZA, Bernardo José de. 2015. Rio de Janeiro, um ano qualquer no futuro. Uma cidade parcialmente submersa, esvaziada da presença humana. In: EAV Curador Visitante. Escola de Artes Visuais do Parque Lage. Curador Visitante. Rio de Janeiro, Brasil. a. 1, n. 2.

SZTUTMAN, Renato. 2019. "Um acontecimento cosmopolítico: O manifesto de Kopenawa e a proposta de Stengers”. Mundo Amazónico v. 10, n. 1: 83-105.

TURNER, Terence; KOPENAWA, Davi. 1991. "I Fight Because I Am Alive': An Interview with Davi Kopenawa Yanomami”. Cultural Survival Quarterly n. 91: 59-64.

VIVEIROS DE CASTRO, Eduardo. 2006. "A floresta de cristal: notas sobre a ontologia dos espíritos amazônicos”. Cadernos de Campo (USP) v. 14/15: 319-338.

VIVEIROS DE CASTRO, Eduardo. 2015. O recado da mata. Prefácio. In: KOPENAWA, Davi; ALBERT, Bruce. 2010 [2015]. A queda do céu: palavras de um xamã yanomami. São Paulo, Companhia das Letras. p. 11-41

Recebido em 27/02/2020

Aceito em 11/05/2020 
